\title{
RDX remote Raman detection on NATO SET-237 samples
}

\author{
Emanuela C. A. Gallo, Luca M. L. Cantu ${ }^{a}$, Frank Duschek \\ DLR (German Aerospace Center), Institute of Technical Physics, Im Langen Grund, 74239 Hardthausen, \\ Germany
}

Received: 14 February 2021 / Accepted: 23 March 2021

(C) The Author(s) 2021

\begin{abstract}
Ultraviolet Raman spectroscopy measurements have been taken at DLR in Lampoldshausen to detect NATO SET-237 standard samples of RDX. The main goal was to quantify the minimum requirements for an unambiguous identification in remote detection $(60 \mathrm{~cm}$ distance) with a commercial Czerny-Turner spectrometer coupled with a CCD camera. Welldefined distribution of explosives on surfaces was tested as standardized samples. Therefore, Raman spectra of RDX have been acquired for different sample concentrations $(50,250$ and $1000 \mu \mathrm{g} / \mathrm{cm}^{2}$, respectively) and under several laser energies $(1.5,3.0$ and $5.0 \mathrm{~mJ} / \mathrm{pulse}$, respectively) at $355 \mathrm{~nm}$ excitation wavelength. The lowest possible reproducible surface concentration $\left(50 \mu \mathrm{g} / \mathrm{cm}^{2}\right)$ was detected with excitation energy of $3 \mathrm{~mJ} /$ pulse in the described configuration.
\end{abstract}

\section{Introduction}

The use of explosives and precursor materials is increasing to intentionally harm people and damage properties. In order to prevent attacks, a reliable detection and identification system is needed. However, the detection of these materials and their precursors remains a challenge. Often, only traces of hazardous materials are available to prevent an immediate threat. Hence, there is a high demand on the sensitivity of the detection technologies. At the same time, a high specificity is necessary in order to discriminate an explosive from an interfering background or harmless substances. Therefore, obtaining a well-defined spectral signature that leads to a clear identification and a low rate of false alarm is very difficult from large molecules like explosives; moreover, the background material might cover, absorb or distort the signal causing more uncertainty. Different types of technology should be employed depending on the type of hazardous compound and environmental conditions. In addition, it is desirable to achieve the widest possible range of detectable hazardous substances and, at the same time, to reduce the acquisition time and laser energy. For these reasons, a comprehensive investigation of the detection possibilities and their optimization for the various warfare agents are mandatory [1]. Among all the available technologies [1, 2], the ones with the best potential of being fast and able to detect and identify many explosive compounds and

Emanuela C. A. Gallo and Luca M. L. Cantu have contributed equally to this work.

\footnotetext{
a e-mail: luca.cantu@dlr.de (corresponding author)
} 
upgradable to new threats are laser-based spectroscopic methods for trace detection. In this context, the presented work is focused on short-pulse Raman spectroscopy chosen for remote detection. Raman spectroscopy was selected for its unique capability of being fast-responsive, highly sensitive, selective and able to identify different explosive compounds [3, 4]/chemical threats [5]. The final goal is to find the minimal detectable amount of the target compound $\left(\mu \mathrm{g} / \mathrm{cm}^{2}\right)$ and minimal energy density $\left(\mathrm{mJ} / \mathrm{cm}^{2}\right)$ required for a clear identification and (in a future step) classification. For this purpose, several samples of perhydro-1,3,5-trinitro-1,3,5triazine $(\mathrm{RDX})[6]$ were tested. The preparation of the samples adds an additional challenge: different methods such as dropping and drying (drop casting) or spray deposition present an easy and fast procedure [1]; however, both methods are not the most recommended choice in terms of reproducibility of the sample type since they provide inhomogeneous distributions (coffee ring pattern) [7]. Among these possibilities, drop-on-demand (DOD) inkjet printing is becoming a promising method for producing standardized test materials with high precession, reproducibility [8] and accuracy [9], especially at very low concentrations. Hence, all the RDX samples here presented were prepared in different concentrations as NATO SET-237 [10] standards using the DOD inkjet printing method developed by the Fraunhofer Institute of Chemical Technology (ICT) [11]. The thresholds and limits of selectivity and sensitivity are recorded and discussed, as well as the associated laser energy and the detection distance (fixed at $60 \mathrm{~cm}$ in this work) for the respective explosive and background.

\section{Experimental setup}

A sketch of the Raman system setup [12] is shown in Fig. 1. An injection seeded Nd:YAG laser (Spectra Physics Quanta Ray Pro 230) with a repetition rate of $10 \mathrm{~Hz}$ (pulse duration < $8 \mathrm{ns)}$ was frequency-doubled to produce a 532-nm laser beam; this beam was used to pump a narrowband dye laser (Sirah Cobra-Stretch). The green light beam left over after the doubling was internally frequency-tripled to produce a 355-nm laser beam. The UV light was then sent to a second exit of the laser and frequency-mixed with the output of the dye laser inside a commercial mixing module (Sirah SFM-355). Depending of the choice of the dye solution or dye mixture, the mixing module is able to produce UV light in the range from 200 to $240 \mathrm{~nm}$. The choice of the output wavelength varies by experimental requirements and by the compound under examination (signal optimization). After exiting the mixing module, the UV laser beam was relayed by a series of UV mirrors first through a beam attenuator (consisting on a rotating half-wave plate and a polarizer) to control the energy (or energy density) of the laser beam and then through a telescope (consisting of two lenses of $150 \mathrm{~mm}$ and $75 \mathrm{~mm}$ focal length, FL) to reduce by half the beam size and to collimate it to the sample. Finally, the 8-mm-diameter collimated UV laser beam was sent to the sample to excite the Raman transition. It can be noticed that the beam is not focused onto the sample in order to do not destroy or damage it and to increase the sampling area.

The generated Raman signal was collected by a 75-mm-diameter, 200-mm FL lens placed at a distance of about $60 \mathrm{~cm}$ from the sample. Subsequently, a couple of lenses collimated the signal, which is finally focused on a $200-\mu \mathrm{m}$ Czerny-Turner spectrometer's (Horiba iHR550) slit by a 75-mm FL lens. A blocking UV filter (blocking wavelength depended on the exiting beam) was placed in front of the slit in order to eliminate residual scattered laser light. Inside the spectrometer, the Raman signal was first dispersed by a 2400 groves $/ \mathrm{mm}$ holographic grating (blaze $250 \mathrm{~mm}$, resolution $0.06 \mathrm{~nm}$ ) and then focused on a couple charged device (CCD) Horiba Symphony II. The camera $(2048 \times 512$ pixel array, maximum resolution $0.01 \mathrm{~nm}$ ) was vertically binned in order to collect a spectrum from the Raman signal. The 


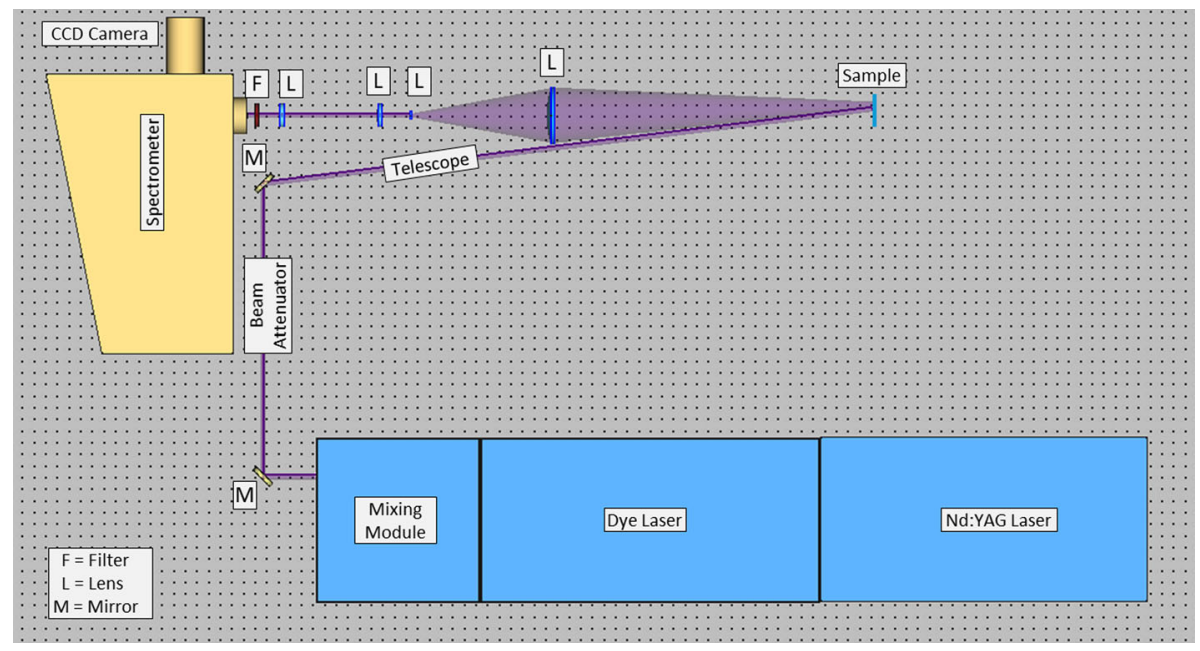

Fig. 1 Sketch of the Raman optical setup

Table 1 RDX sample characteristics

\begin{tabular}{lllllrc}
\hline RDX Sample \# & Solvent & $\begin{array}{l}\text { Concentration Array } \\
(\mathrm{mg} / \mathrm{ml})\end{array}$ & Droplets per point & Layers & $\begin{array}{l}\text { Final distribution } \\
\left(\mu \mathrm{g} / \mathrm{cm}^{2}\right)\end{array}$ \\
\hline 832 & ACN & 10 & $40 \times 44$ & 2 & 4 & 50 \\
835 & MEK & 20 & $34 \times 36$ & 6 & 5 & 250 \\
838 & MEK & 20 & $34 \times 35$ & 4 & 10 & 1000 \\
\hline
\end{tabular}

overall resolution of the system for the acquired spectra was $15 \mathrm{~cm}^{-1}$. Acquisition time varied from a minimum of $1 \mathrm{~s}$ to a maximum of $30 \mathrm{~s}$ depending on the sample type, concentration, distance, and laser energy.

\section{Explosive samples}

The laboratory samples presented in this study were produced as NATO SET-237 [10] by the Fraunhofer ICT using a GeSiM 2.1 Nano-Plotter ( 40-500 pico-liters per droplet) DOD inkjet printer [11]. Since the printing method is completely contactless, extremely small droplets of concentrated material can be homogeneously spread over a wide selection of solid backgrounds in different patterns. The requirement is a homogeneous coating of the substrate with a precisely predefined concentration and a uniform particle size. The solvent in use for the samples under examination was acetonitrile (ACN) and methyl ethyl ketone (MEK). The threat concentration (and droplet volume) varies from 10 to $30 \mathrm{mg} / \mathrm{ml}$, and it was determined by means of stroboscope observation with optical sensor as well as by a flow sensor. The plotting speed is determined by the analyte itself and its concentration into the solvent as well as the number of droplets per point and the number of layers printed. Table 1 summarizes the characteristics of the produced samples and the different printing parameters chosen for RDX. 

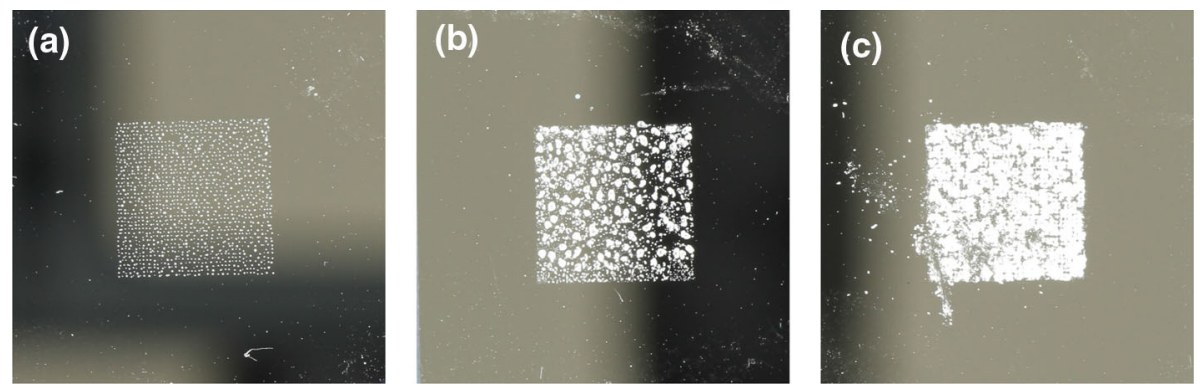

Fig. 2 Macro-pictures of RDX NATO-237 samples a \#832 $\left(50 \mu \mathrm{g} / \mathrm{cm}^{2}\right)$; b \#835 $\left(250 \mu \mathrm{g} / \mathrm{cm}^{2}\right)$; c \#838 $\left(1000 \mu \mathrm{g} / \mathrm{cm}^{2}\right)$

At the beginning of a plotting process, droplets of the solution are formed. By evaporation of the solvent, these droplets shrink and finally solid residues remain on the substrate. Finally, the second layer is printed again and the procedure is repeated till the desired final distribution is obtained. The first NATO SET-237 of RDX samples are shown in Fig. 2. In this sample preparation, the explosives were printed on an area of $1 \times 1 \mathrm{~cm}$ over an aluminum substrate.

\section{Samples' analysis}

All the samples were first analyzed to verify the compound distribution and physical properties. A preliminary analysis using the microscope Krüss Optronic MSZ 5400 was done to determine the overall distribution on the sample over the background surface. An Edinburgh Instrument Spectrofluorometer FS5 was employed to measure the absorbance of all tested materials. This information was useful to select the best laser wavelength to maximize the Raman signal. Figure 3 compares the samples of RDX in different concentrations using the-Krïss Optronic MSZ 5400 microscope-with a 40× magnification. The main goal was to verify the integrity and the uniformity of the droplet distribution of the samples.

It can be observed that obtaining a similar distribution over the sample is quite challenging for RDX. The microscope images show different droplets size in the sample, and this effect could be attributed to the high melting point temperature of $\operatorname{RDX}\left(206^{\circ} \mathrm{C}\right)[6]$. Most industrial printing devices use piezo-electrically or thermally generated pressure pulses to eject droplets from a fluid cavity: During this procedure, the solution solvent explosive is heated up to $40^{\circ}-50{ }^{\circ} \mathrm{C}$. Under this condition, RDX is still in solid form; hence, its conglomerate may result in partial droplet released. In addition, looking from Fig. 3a-c, it can be inferred that at higher overall explosive distribution it is not possible to achieve uniformity of the sample.

(a)

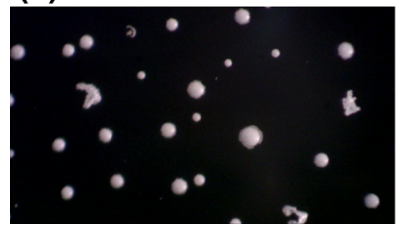

(b)

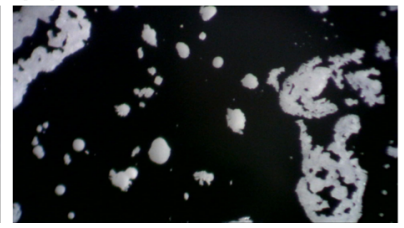

(c)

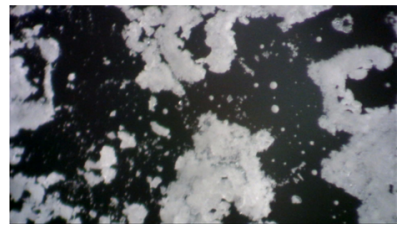

Fig. $340 \times$ selected views of RDX samples a \#832 $\left(50 \mu \mathrm{g} / \mathrm{cm}^{2}\right) ; \mathbf{b} \# 835\left(250 \mu \mathrm{g} / \mathrm{cm}^{2}\right) ; \mathbf{c} \# 838\left(1000 \mu \mathrm{g} / \mathrm{cm}^{2}\right)$ 


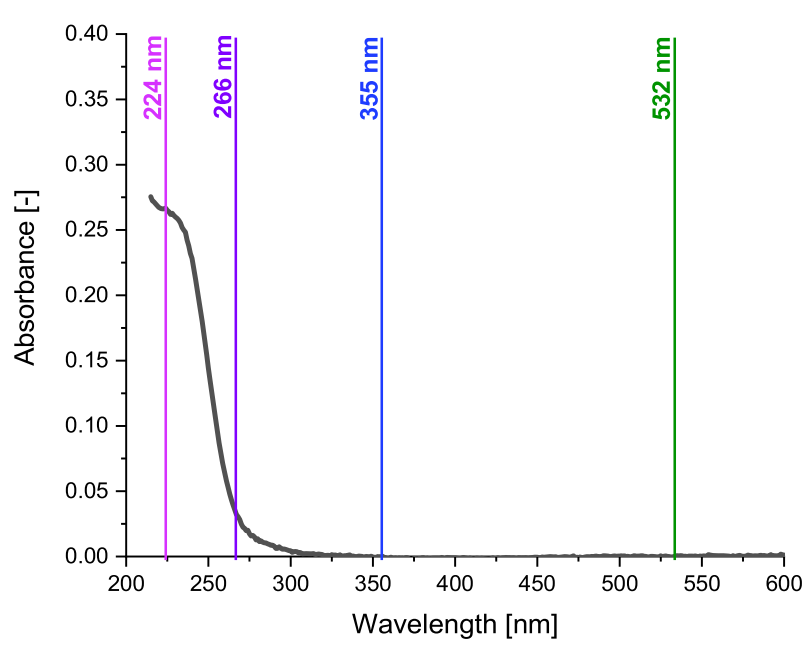

Fig. 4 Absorbance spectrum of RDX. Vertical lines represent the frequently used Raman excitation wavelengths. Results for $355 \mathrm{~nm}$ are presented

The images show a more uneven distribution of particles and uneven size of the droplets with increasing amount of the deposited material. The multilayer approach to produce higher concentration is unable to provide a uniform distribution, and the particles of RDX tend to cluster together. The subsequent evaporation of the solvent has the only effect to spread the material over the background surface creating local inhomogeneous patterns. However, all the samples were well confined into the $1 \mathrm{~cm}^{2}$, and the achieved distribution, although non-fully-uniform, was found much better that the one obtained by the drop-cast method [7].

The Edinburgh Instrument Spectrofluorometer FS5 was employed to obtain the absorbance spectrum of the samples. The explosive was tested using the compound dissolved into a solution. Concentrated solution of RDX in ACN was prepared and tested inside a cuvette. A cuvette filled with pure ACN was tested as reference background. The concentration was experimentally found based on the strength of the transmission spectrum. Exceeding an imposed value implied saturating the spectrometer (hence damaging it). Concentration of RDX was set to $5.44 \times 10^{-3} \mathrm{mg} / \mathrm{ml}\left(2.45 \times 10^{-5} \mathrm{~mol} / \mathrm{l}\right)$. Transmittance was measured inside the spectrofluorometer scanning each wavelength produced by a Xenon lamp from 215 to $900 \mathrm{~nm}$ with $1 \mathrm{~nm}$ step. At each wavelength, the light illuminated the sample for $0.5 \mathrm{~s}$. From the measured transmittance, it was possible to calculate the absorbance. Figure 4 shows the absorbance spectrum of RDX. The absorbance peak of RDX is at $215 \mathrm{~nm}$ (deep UV). Moving toward the visible wavelengths, the absorbance drops fast and almost no light is absorbed after $380 \mathrm{~nm}$. The values are also in agreement with Lu et al. [13]. However, although the peaks of the absorbance are a good indication about the strength of the Raman signal, they are also providing the strongest fluorescence. Hence, in order to avoid strong interfering fluorescence from the sample, laser sources in the range of $355 \mathrm{~nm}$ could be a good compromise between strength of the Raman signal and low fluorescence. 


\section{Results and discussion}

Raman measurement was taken using different concentrations of explosive samples $(50,250$ and $1000 \mu \mathrm{g} / \mathrm{cm}^{2}$, respectively) and different energies (1.5, 3.0 and $5.0 \mathrm{~mJ} / \mathrm{pulse}$ ) of the exciting laser ( $355 \mathrm{~nm}$ wavelength at $10 \mathrm{~Hz}$ repetition rate). The exciting laser beam was collimated to $8 \mathrm{~mm}$ diameter yielding an energy density of 30,60 and $100 \mathrm{~mW} / \mathrm{cm}^{2}$, respectively. The Raman signal was collected at a distance of about $60 \mathrm{~cm}$ from the target sample inside a spectrometer coupled with a CCD camera with an acquisition time of $30 \mathrm{~s}$. Samples \#832, \#835 and \#838 were chosen as representative of 50, 250 and $1000 \mu \mathrm{g} / \mathrm{cm}^{2}$ of RDX concentration, respectively. Figure 5 shows the Raman spectra of RDX \#832 $\left(50 \mu \mathrm{g} / \mathrm{cm}^{2}\right)$ tested at different laser energies. The black line represents the raw data, while the thick red line represents a smoothing function consisting of an average of \pm 5 adjacent points. The most known peaks [7] of the compound are marked in red.

It can be noticed that the Raman signature of RDX is evident in both plots. The main peak at $885 \mathrm{~cm}^{-1}$ (mainly $\mathrm{CN}$ stretch) can be recognized by the background level as well as the peaks at 1267 (NN stretching and ONO stretching, maybe with $\mathrm{CH}_{2}$ twist) and $1310 \mathrm{~cm}^{-1}$ $\left(\mathrm{CH}_{2}\right.$ wag or combination) $[14,15]$. However, at lower laser energy, all the other spectral features are not distinguishable from the background even with the help of the smoothing function (red line). This suggests that $3 \mathrm{~mJ} /$ pulse is still not enough to have a clear spectral signature and more energy or higher concentration of the hazardous compound is necessary for a better identification. For this reason, the test with laser energy of just $1.5 \mathrm{~mJ} / \mathrm{pulse}$ is not shown: even the main peak at $885 \mathrm{~cm}^{-1}$ was not strong enough to be discriminated from the background noise. On the other hand, Fig. 7c shows much more structured features. Despite the low concentration of RDX, peaks at 944 and $1218 \mathrm{~cm}^{-1}$ are clearly visible, in addition to the three already mentioned main peaks. Having more information about the spectral shapes leads to a better identification of the hazardous compound and reduces the rate of false alarms. Hence, laser energy of at least $5 \mathrm{~mJ} /$ pulse is recommended to detect $50 \mu \mathrm{g} / \mathrm{cm}^{2}$ (or more) RDX in the presented configuration. Figure 6 shows the Raman spectra of RDX \#835 $\left(250 \mu \mathrm{g} / \mathrm{cm}^{2}\right)$ tested at different laser energies.

Again, all the strongest peaks [7] of the RDX at 885, 1267 and $1310 \mathrm{~cm}^{-1}[14,15]$, respectively, are clearly distinguishable from the background in all the three spectra. In addition, peaks at 944 and $1218 \mathrm{~cm}^{-1}$ are strong enough for identification even at $1.5 \mathrm{~mJ} / \mathrm{pulse}$ energy. This implies that low laser energy is required once the concentration of the RDX is

(b)

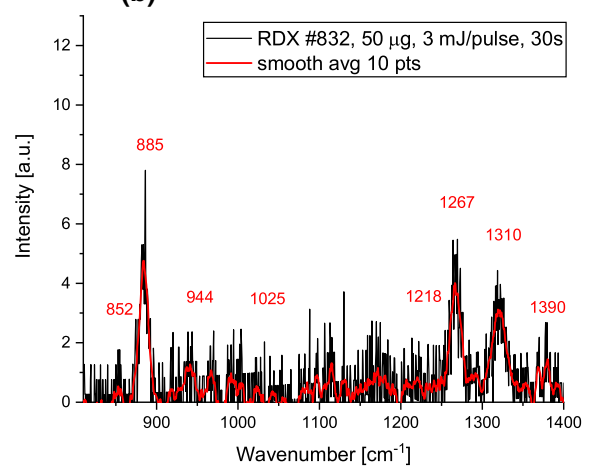

(c)

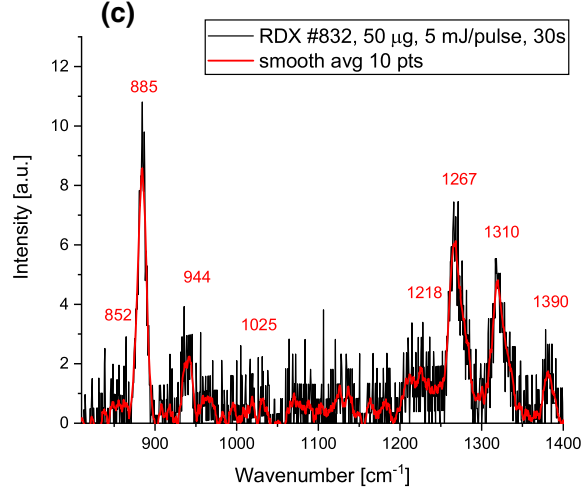

Fig. 5 Raman spectra of $50 \mu \mathrm{g} / \mathrm{cm}^{2}$ of RDX; b laser energy $3 \mathrm{~mJ} /$ pulse; c laser energy $5 \mathrm{~mJ} /$ pulse 

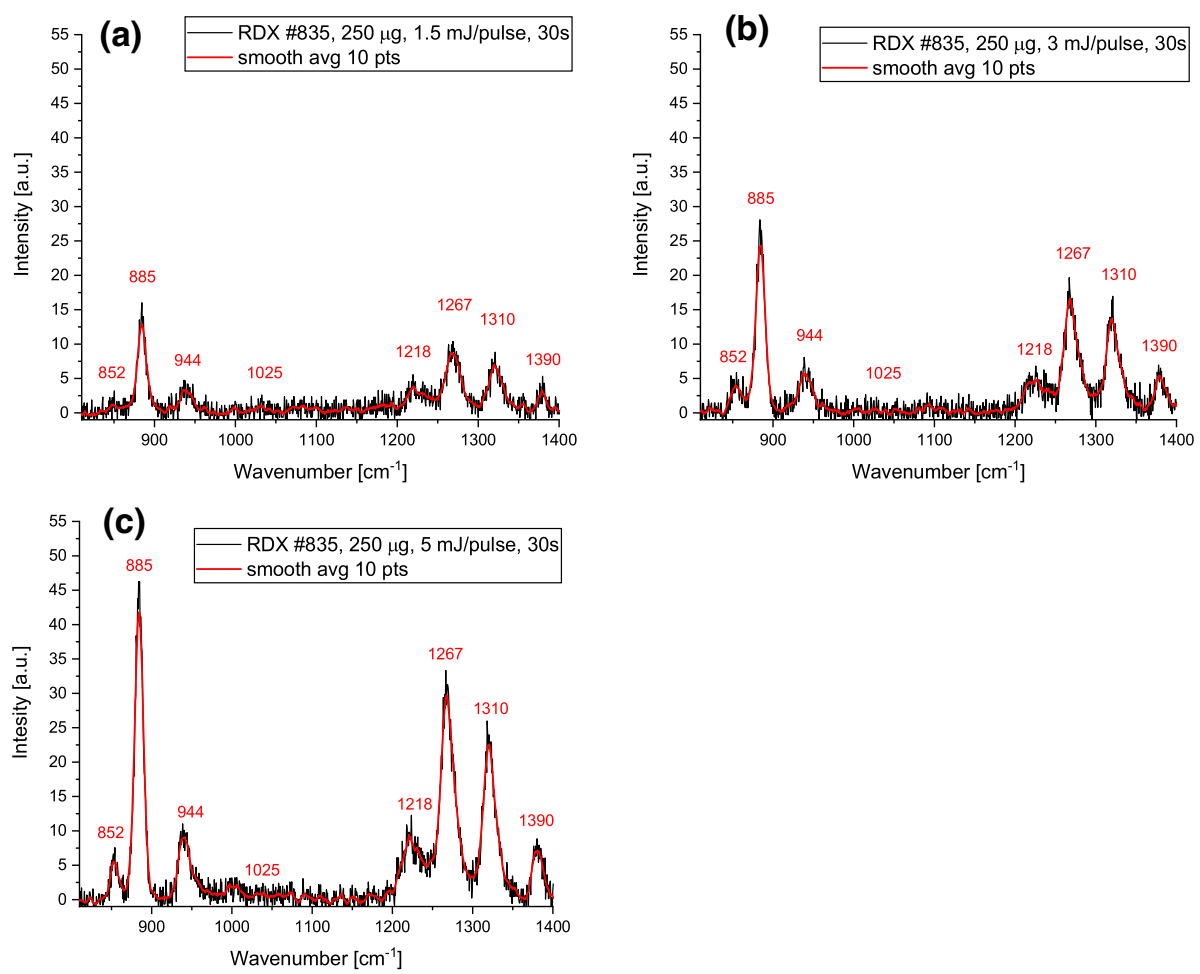

Fig. 6 Raman spectra of $250 \mu \mathrm{g} / \mathrm{cm}^{2}$ of RDX; a laser energy $1.5 \mathrm{~mJ} /$ pulse; b laser energy $3 \mathrm{~mJ} /$ pulse; $\mathbf{c}$ laser energy $5 \mathrm{~mJ} /$ pulse

at least $250 \mu \mathrm{g} / \mathrm{cm}^{2}$. Of course, when more laser energy is used, the spectral features are clearer since the signal-to-noise ratio is much higher, as it can be noticed in Fig. 8b, c, where peaks at 852 (NN stretch plus $\mathrm{NO}_{2}$ axial scissoring) and $1218 \mathrm{~cm}^{-1}$ (NC stretching) [14, 15] are stronger in intensity. Increasing the laser energy up to $5 \mathrm{~mJ} /$ pulse makes the peak at 1025 $\mathrm{cm}^{1}$ (NC stretch with some $\mathrm{CH}_{2}$ rocking) $[14,15]$ visible, even though it is not completely discriminated by the background noise. In conclusion, the Raman system is sensitive enough to detect at least $250 \mu \mathrm{g} / \mathrm{cm}^{2}$ of RDX using just $1.5 \mathrm{~mJ} /$ pulse laser energy. Figure 7 shows the Raman spectra of RDX \#838 $\left(1000 \mu \mathrm{g} / \mathrm{cm}^{2}\right)$ tested at different laser energies.

In this last case, RDX is concentrated enough to be detected at each tested laser energy. The signal-to-noise ratio is high in all the three pictures. Interesting that at these conditions the peak at $1025 \mathrm{~cm}^{-1}$ can be used as an additional discrimination factor to identify the compound. An additional peak is also visible at $1390 \mathrm{~cm}^{-1}$ (CH2 twisting) [14, 15]. Hence at a concentration of at least $1000 \mu \mathrm{g} / \mathrm{cm}^{2}$, the Raman system required $1.5 \mathrm{~mJ} /$ pulse to be sensitive enough to clearly identify RDX at $60 \mathrm{~cm}$ distance. As shown in Sect. 4, the sample material to be examined was non-homogeneously distributed on the substrate surface. For the NATO-printed standard samples, their nominal density value is given in $\mu \mathrm{g} / \mathrm{cm}^{2}$. RDX was distributed more or less evenly over the substrate surface, depending on the efficiency of the printing process on the $1 \times 1 \mathrm{~cm}^{2}$ sample area. As a first approximation, the signal depends on the area of the sample that interacts with the incident excitation light as shown 

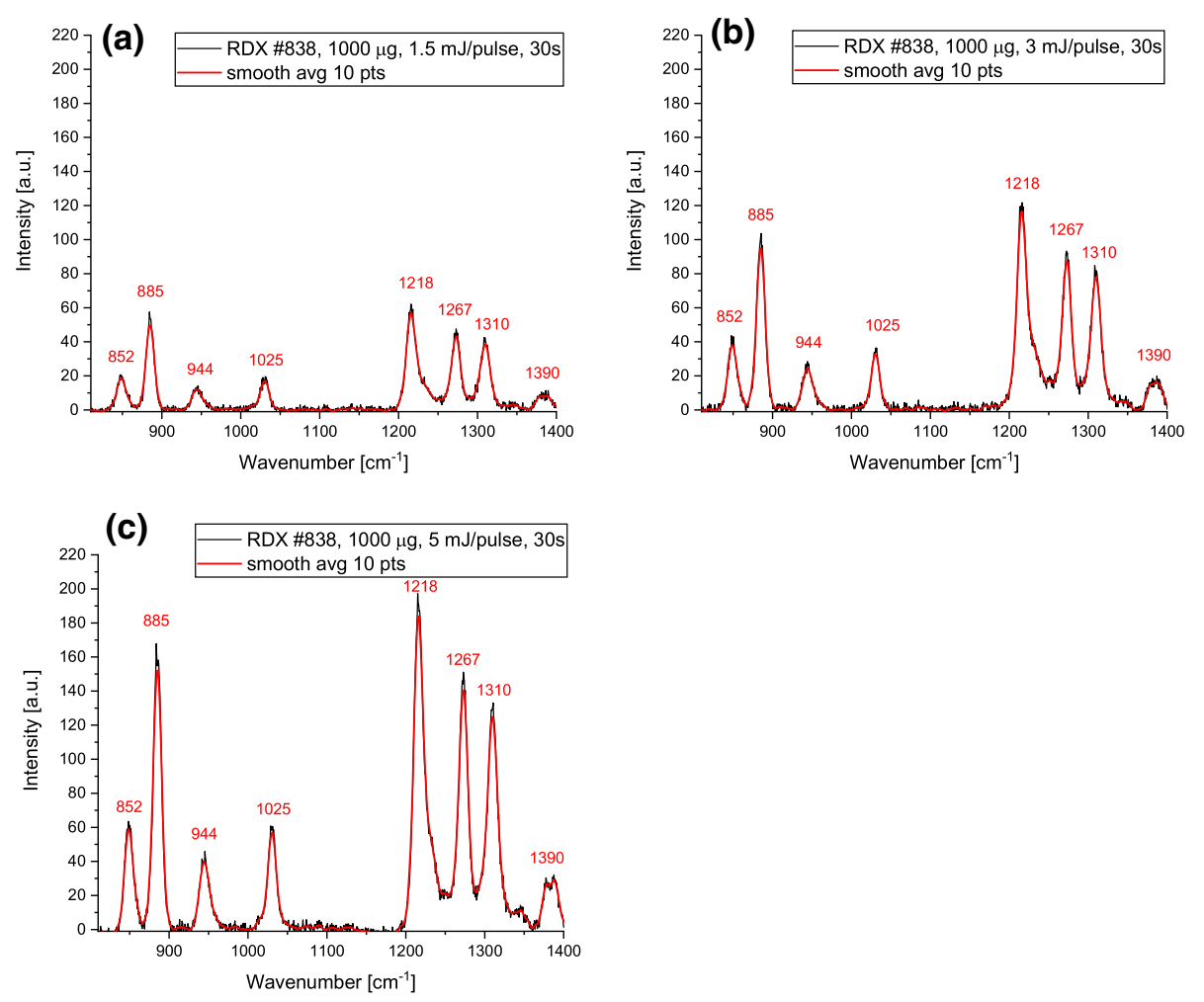

Fig. 7 Raman spectra of $1000 \mu \mathrm{g} / \mathrm{cm}^{2}$ of RDX; a laser energy $1.5 \mathrm{~mJ} /$ pulse; b laser energy $3 \mathrm{~mJ} /$ pulse; c laser energy $5 \mathrm{~mJ} /$ pulse

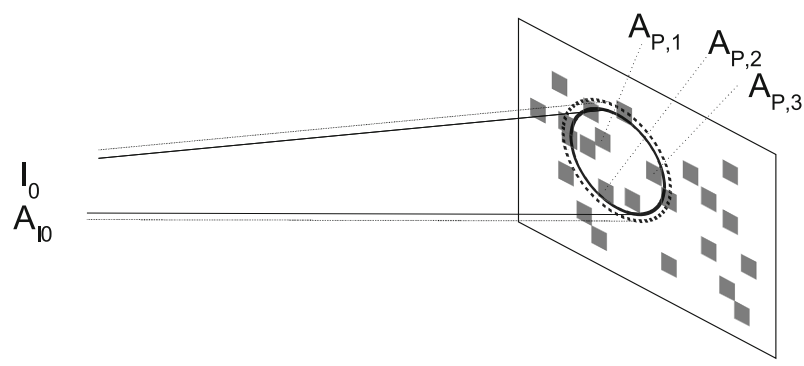

Fig. 8 Sketch of the area ratios on a non-homogeneous RDX-printed sample. Intensity of the exciting laser $I_{0}$, area of the laser on the sample $A_{\mathrm{I} 0}$, area of the individual sample particles on the background $A_{p, I}$

in Fig. 8. The effective sampled area was below the total available area $\left(1 \mathrm{~cm}^{2}\right)$ because the incident laser beam was smaller $\left(0.5 \mathrm{~cm}^{2}\right)$.

In the case of resonance Raman scattering (and fluorescence), absorption effects must also be considered. For RDX, the penetration depth is specified in the literature [16] to be $\sim 1.1 \mu \mathrm{m}$. Taking this factor into consideration, the nominal explosive density value (specified for the NATO-given samples in $\mu \mathrm{g} / \mathrm{cm}^{2}$ ) is only a limited measure for specifying the sensitivities of the measurement process. Practically, only the illuminated surface and a minimal part of the thickness contribute to the Raman signal, while all the materials found below the penetration 


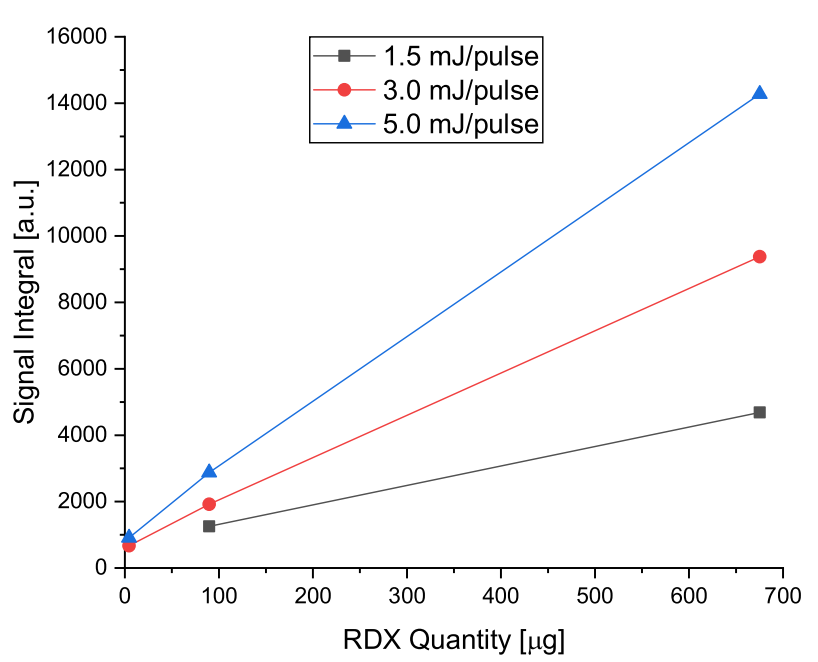

Fig. 9 Detectable Raman signals of RDX as a function of effective quantity at different excitation laser pulse energies

depth are not detected. Using the images from the microscope analysis, it was possible to compute the effective detectable quantity of explosives taking also into consideration that the area of the incident laser beam $\left(0.5 \mathrm{~cm}^{2}\right)$ was smaller than the sample size. Figure 9 shows the dependency of the Raman signals of RDX as a function of the effective detectable quantity in $\mu \mathrm{g}$.

It can be noticed that the minimal amount detectable is $4.4 \mu \mathrm{g}$ of RDX using at least $3 \mathrm{~mJ} /$ pulse energy. However, it requires a minimum of $89.7 \mu \mathrm{g}$ of RDX to be detected by the minimum laser energy tested $(1.5 \mathrm{~mJ} /$ pulse $)$.

\section{Summary}

An experimental setup for remote Raman spectroscopy with short pulse systems was optimized for the investigation of explosives on contaminated surfaces. First results were presented in this study to identify the detection limits (laser energy and compound's concentration) for RDX. The measurements were taken on printed RDX NATO SET-237 samples. The Raman signature of the explosive corresponds to the signature of the pure substance known from the literature. The minimum detectable RDX was $4.4 \mu \mathrm{g}$ with exciting laser energy of $3 \mathrm{~mJ} /$ pulse. However, the signal-to-noise ratio was found too low for a clear identification, so $5 \mathrm{~mJ} /$ pulse is suggested to avoid false alarms. Increasing further the concentration of RDX (at least $89.7 \mu \mathrm{g}$ ) provided always a clear identification of the explosive material even with $1.5 \mathrm{~mJ} /$ pulse. A further optimization of the system (pulse energies and pulse diameter, collecting optics, detection device) will be performed to possibly decrease the detectable amount limits. Moreover, the preparation of a suitable sample plays an essential role in determining the sensitivities of the technologies used, and their specified standard concentration $\left(\mu \mathrm{g} / \mathrm{cm}^{2}\right)$ is not a realistic measure for the effective detection sensitivity, especially in the case of inhomogeneous surfaces with thick sample particles. A better estimation of the sensitivity can be determined on homogeneous layers with a thickness equal to the penetration depth of the exciting laser light. 
Acknowledgements This research work was supported by the Bundeswehr Research Institute for Protective Technologies and CBRN Protection (WIS), Munster, Germany. The authors are particularly thankful to Björn Prietzel (DLR-TP-APW) for his support in the chemical laboratory and for operating the spectrofluorometer, Kirsten Klaffki (DLR-TP-APW) for the images with the laser microscope and Dr. Christian Ulrich (Fraunhofer ICT) for printing the NATO SET-237 standard.

Funding Open Access funding enabled and organized by Projekt DEAL.

Open Access This article is licensed under a Creative Commons Attribution 4.0 International License, which permits use, sharing, adaptation, distribution and reproduction in any medium or format, as long as you give appropriate credit to the original author(s) and the source, provide a link to the Creative Commons licence, and indicate if changes were made. The images or other third party material in this article are included in the article's Creative Commons licence, unless indicated otherwise in a credit line to the material. If material is not included in the article's Creative Commons licence and your intended use is not permitted by statutory regulation or exceeds the permitted use, you will need to obtain permission directly from the copyright holder. To view a copy of this licence, visit http://creativecommons.org/licenses/by/4.0/.

\section{References}

1. P.M. Pellegrino, E.L. Holthoff, M.E. Farrell, Laser-Based Optical Detection of Explosives (CRC Press, New York, 2015).

2. P. Zang, Y. Tang, A. Shi, L. Bao, Y. Shen, R. Shen, Y. Ye, Recent developments in spectroscopic techniques for the detection of explosives. Materials 11(8), 1364 (2018). https://doi.org/10.3390/ma11081364

3. K.L. Gares, K.T. Hufziger, S.V. Bykov, S.A. Asher, Review of explosive detection methodologies and the emergence of stand-off deep UV resonance Raman. J. Raman Spectrosc. 47, 124-141 (2016). https://doi. org/10.1002/jrs.4868

4. J.K. Chung, S.G. Cho, Standoff Raman spectroscopic detection of explosive molecules. Bull. Korean Chem. Soc. (2013). https://doi.org/10.5012/bkcs.2013.34.6.1668

5. F. Kullander, H. Lunden, P. Wästerby, L. Landström, Ultraviolet Raman Scattering from V-Agents, in Proceedings of the SPIE, vol. 10183 (2017) https://doi.org/10.1117/12.2262123

6. Perhydro-1,3,5-trinitro-1,3,5-triazina, ECA (European Chemical Agency). https://echa.europa.eu/briefprofile/-/briefprofile/100.004.092

7. W. Fountain III., S.D. Christiansen, R.P. Moon, J.A. Guichetau, E.D. Emmons, Recent advancements and remaining challenges for the spectroscopic detection of explosive threats. Appl. Spectrosc. 68(8), 795-811 (2014). https://doi.org/10.1366/14-07560

8. E. Windsor, M. Najarro, A. Bloom, B. Brenner Jr., R. Fletcher, R. Lareau, G. Gillen, Application of inkjet printing technology to produce test materials of 1,3,5-trinitro-1,3,5 triazcyclohexane for trace explosive analysis. Anal. Chem. 82(20), 8519-8524 (2010). https://doi.org/10.1021/ac101439r

9. E. L. Hothoff, M. E. Hankus, K. Q. Tober, P. M. Pellegrino, Investigating a drop-on-demand micro dispenser for standardized sample preparation, in ARL-TR-5726, Adelphi MD (2011) https://doi.org/10. $1117 / 12.918121$

10. NATO SET-237 Printed Standards for Standoff Detection, Document AC/323-D(2018)0001 (2018)

11. F. Schnürer, C. Ulrich, S. Müller, W. Schweikert, Printed explosives standards for the evaluation of stand-off optical systems, in Proceedings of the SPIE, vol 10802 (2018) https://doi.org/10.1117/12. 2325305

12. E. C. A. Gallo, C. Kölbl, F. Duschek, A. Köhntopp, A. Walter, UV Raman spectroscopy for explosives, in 3rd International Conference CBRNE - Research \& Innovation, Poster, Nantes, France (2019)

13. T. Lu, Z. Wen, L. Wan, X. He, Y. Yuan, M. Wang, Y. Zhao, M. Li, X. Pu, T. Xu, Quantitative determination on binary-component polymer bonded explosives: a joint study of ultraviolet spectrometry and multivariate calibration methods. Chemom. Intell. Lab. Syst. 147, 131-138 (2015). https://doi.org/10.1 016/j.chemolab.2015.08.011

14. D. Tuschel, A.V. Mikhonin, B.E. Lemoff, S.A. Asher, Deep ultraviolet resonance Raman excitation enables explosives detection. Appl. Spectrosc. 64(4), 425-432 (2010). https://doi.org/10.1366/0003702 10791114194

15. A.Z. Dreger, M.Y. Gupta, High pressure Raman spectroscopy of single crystals of hexahydro-1,3,5trinitro-1,3,5-triazine (RDX). J. Phys. Chem. B 111, 3893-3903 (2007). https://doi.org/10.1021/jp0681 092 
16. M. Amin, P. Wen, W.D. Herzog, R.R. Kunz, Optimization of ultraviolet Raman spectroscopy for trace explosive checkpoint screening. Anlytical and Bioanal. Chem. 412, $4495-4504$ (2020). https://doi.org/ $10.1007 / \mathrm{s} 00216-020-02725-2$ 